\title{
US zoos keep watch for cross-species killer
}

\section{Jonathan Knight, Salt Lake City}

American zoos have begun monitoring for outbreaks of West Nile virus, which has killed thousands of birds and 18 people in the United States since 1999. It is the first time that zoos have been used for surveillance of a zoonotic disease - one that can pass from animals to people.

Current monitoring relies largely on reports of crow deaths from the public, but this approach may be less effective in the western United States, where the public is only dimly aware of the disease. "With wild animals you need a pretty big die-off before anyone notices, and you lose that window of opportunity for rapid response," says Tracey McNamara, a veterinary pathologist at Bronx Zoo in New York, who helped to develop the zoo-based monitoring scheme.

West Nile virus is endemic throughout Africa and parts of Europe, but had never been seen in the Americas before 1999. That summer, wild crows began dying in New York, but state epidemiologists were unable to determine the cause. The breakthrough came when McNamara dissected the brains of crows that dropped dead on her zoo's grounds and found lesions consistent with viral infection. By early September, a Guanay cormorant, three Chilean flamingos and a bald eagle had also died.

McNamara suspected a link to the simultaneous outbreak of human encephalitis in the area and confirmed that viral particles in the birds' brains were the same size as those from human patients. The Centers for Disease Control and Prevention (CDC) in Atlanta identified both viruses as West Nile.

State public-health agencies have tracked the disease mainly by examining dead crows and mosquitoes, which can spread the virus. Insecticides are used to control infected mosquito populations. But birds can infect one another directly, and the virus is still spreading through the United States. In 1999, it was found in only four states, but by the end of 2001 it had turned up in 27, reaching as far south as Florida and west to Iowa.

All zoos monitor their animals closely for illness, principally by taking regular blood samples. Participants in McNamara's programme now also send blood to Cornell University's veterinary diagnostic lab in Ithaca, New York, to be tested for antibodies against West Nile virus or for the virus itself.

Together with Dominic Travis, a veterinary epidemiologist at Lincoln Park Zoo in Chicago, McNamara started the programme in September with a network of six zoos. It now includes 64 zoos nationwide, with 20 more about to join. By March, some 4,500 samples had been submitted, of which more than 60 tested positive, McNamara told the annual meeting of the American Society for

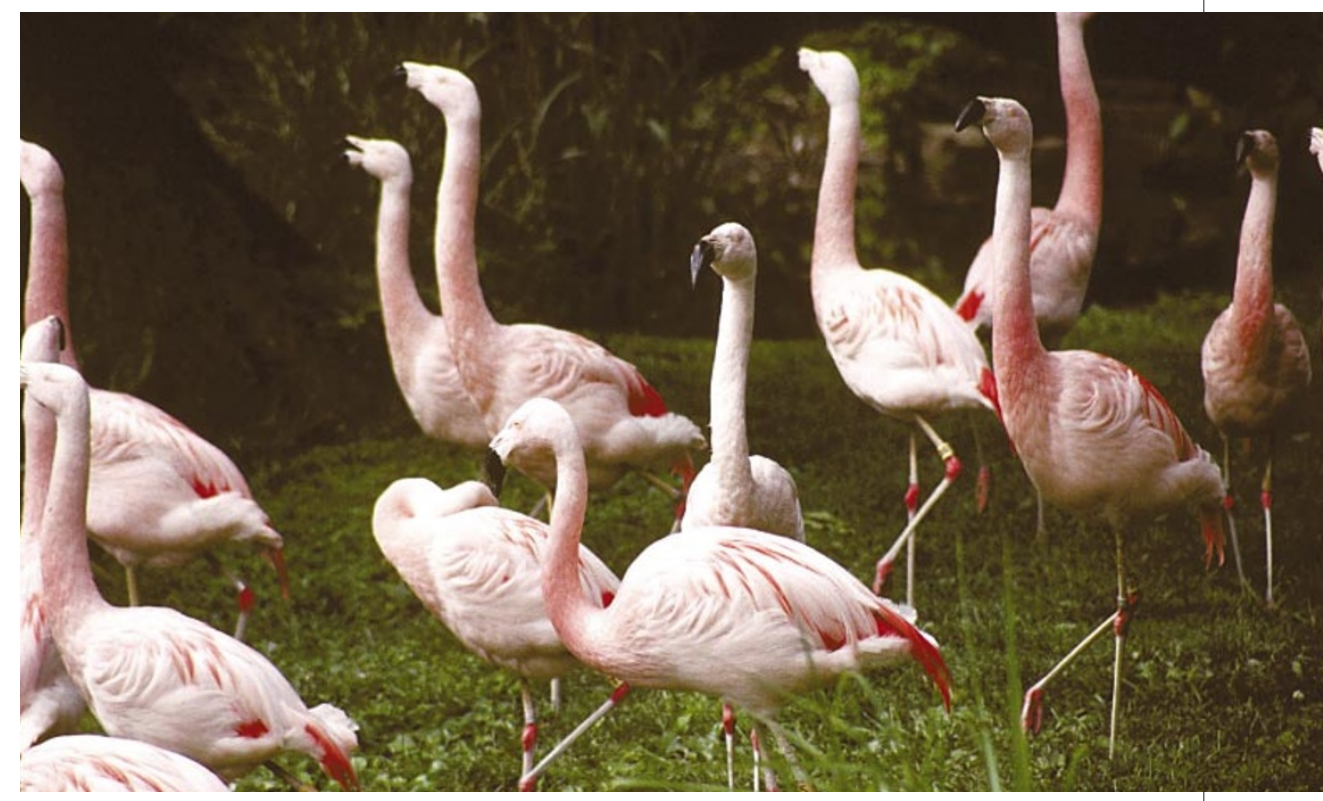

In the pink: but West Nile virus has killed others from this Chilean flamingo flock at Bronx Zoo.

Microbiology in Salt Lake City last week. So far, the system has not identified an infection outside the known endemic area. But the real test is just beginning, as mosquitoes become more active in the summer.

The CDC has agreed to spend $\$ 50,000$ on the pilot project, which will cover the cost of

reagents, a technician and shipment of samples. If it proves successful, the scheme could be expanded to include regional testing centres for more rapid detection. "If it looks effective, we are eager to continue it," says the CDC's Jim Hughes, who directs the National Center for Infectious Diseases in Atlanta.

\section{Superbugs reveal chink in armour}

Jonathan Knight

Most antibiotic-resistant lung infections are caused by a handful of bacterial strains, microbiologists now believe, contrary to previous opinion. This homogeneity raises hopes for vaccines, the American Society for Microbiology heard last week in Salt Lake City.

Bacteria can share antibiotic-resistance genes through the transfer of loops of DNA called plasmids. Although the staphylococci that cause hospital-acquired and childhood

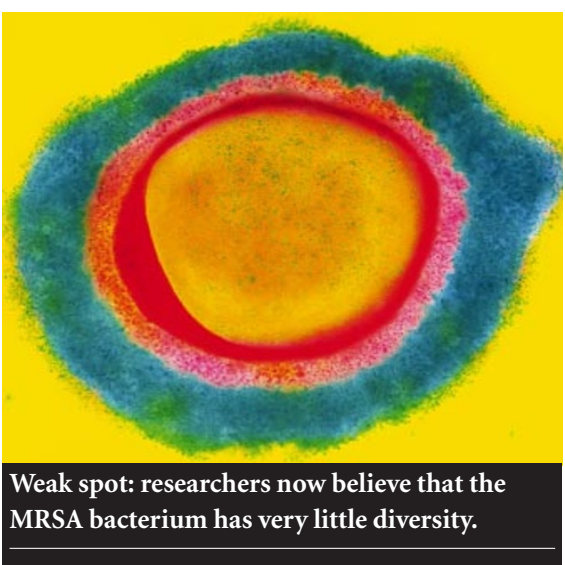

pneumonia do not carry plasmids, they can incorporate plasmid DNA into their genomes. This was thought to explain the worldwide spread of scourges such as methicillinresistant Staphylococcus aureus (MRSA).

It now seems that resistance is spreading not because diverse strains are acquiring plasmids, but through clonal reproduction of a few 'superbugs'. Microbiologist Keith Klugman of Emory University in Atlanta, Georgia, co-founder of the Pneumococcal Molecular Epidemiology Network, presented evidence that about $75 \%$ of drug-resistant childhood pneumonia cases are caused by 10 strains of pneumococcus. Almost half are caused by one strain, Spain 23-F.

Herminia de Lencastre, a molecular biologist at Rockefeller University in New York, said her laboratory tested 3,000 MRSA isolates from 14 countries and found that $70 \%$ of infections belonged to five strains.

Low natural variability makes resistant bacteria good targets for vaccines. Vaccines against MRSA are still under development, but the pneumococcal vaccine Prevnar is showing signs of success against antibioticresistant strains in South Africa. 